Check for updates

Cite this: RSC Adv., 2018, 8, 14249

Received 25th January 2018

Accepted 29th March 2018

DOI: $10.1039 / \mathrm{c} 8 \mathrm{ra00766g}$

rsc.li/rsc-advances

\section{The effect of heat treatment on the anatase-rutile phase transformation and photocatalytic activity of Sn-doped $\mathrm{TiO}_{2}$ nanomaterials}

\author{
Xiaodong Zhu, (D) ab Shihu Han, ${ }^{\text {b }}$ Wei Feng, ${ }^{\text {ac }}$ Qingquan Kong, ${ }^{\text {ac }}$ Zhihong Dong, ${ }^{a}$ \\ Chenxi Wang, ${ }^{a}$ Jiahao Lei ${ }^{a}$ and Qian Yia
}

\begin{abstract}
Sn-doped $\mathrm{TiO}_{2}$ nanomaterials with different amounts of $\operatorname{Sn}(1,2.5,5,10$, and 15 at\%) were prepared by a solgel method and characterized by XRD, TG, DTA, EDS, XPS, DRS, SEM, BET, and PL. The photocatalytic activity of the prepared samples was investigated by measuring the degradation of rhodamine $B$ in aqueous solution under UV light. The experimental results indicate that doping with Sn promotes phase transformation from anatase to rutile. The photocatalytic activity of $\mathrm{TiO}_{2}$ is influenced by both the heat treatment temperature and the $\mathrm{Sn}$ doping concentration. $1 \% \mathrm{Sn}-\mathrm{TiO}_{2}$ exhibits the highest degradation rate at $350{ }^{\circ} \mathrm{C}$ and $5 \% \mathrm{Sn}-\mathrm{TiO}_{2}$ exhibits the best photocatalytic activity at $500{ }^{\circ} \mathrm{C}$ and $650{ }^{\circ} \mathrm{C}$. The enhancement of the photocatalytic activity can be ascribed to a larger surface area and a better hydration ability, as well as less recombination of the photogenerated pairs.
\end{abstract}

\section{Introduction}

Following industrial development, water pollutants have become a serious environmental problem in the last few decades. In terms of the methods used for waste water treatment, using photocatalysts for decomposing harmful organic pollutants into $\mathrm{CO}_{2}$ and $\mathrm{H}_{2} \mathrm{O}$ is one of the most promising strategies. There are several candidate photocatalysts that have been applied to water treatment. ${ }^{1-4} \mathrm{Among}$ them, $\mathrm{TiO}_{2}$ has been extensively studied owing to its high oxidation, non-toxicity, low cost, and chemical stability. ${ }^{5-7}$ However, pure $\mathrm{TiO}_{2}$ is severely restricted in application due to its low solar energy utilization on account of its large bandgap and the fast recombination of photogenerated electrons and holes. ${ }^{8,9}$ Among the several strategies designed to improve the photocatalytic activity of $\mathrm{TiO}_{2}$, ion doping is a convenient and effective approach. ${ }^{10-15}$ Among numerous elements, Sn has been reported to be an effective doping resource and is widely used for enhancing the photocatalytic properties of $\mathrm{TiO}_{2} \cdot{ }^{16-22} \mathrm{Sn}$ doping can promote the photocatalytic activity of $\mathrm{TiO}_{2}$ due to the fact that $\mathrm{Sn}^{4+}$ ions and $\mathrm{Ti}^{4+}$ ions have similar radii. $\mathrm{Sn}^{4+}$ ions are able to enter into $\mathrm{TiO}_{2}$ lattices and create electron traps, resulting in the enhancement of the separation of photogenerated pairs. ${ }^{23,24}$ In addition, the $\mathrm{SnO}_{2}$ band is $3.6 \mathrm{eV}$ and its structure is similar to rutile $\mathrm{TiO}_{2}$ and, therefore, the recombination of the

${ }^{a}$ College of Mechanical Engineering, Chengdu University, Chengdu 610106, China. E-mail:fengwei1981_829@foxmail.com

${ }^{b}$ College of Materials and Chemistry \& Chemical Engineering, Chengdu University of Technology, Chengdu 610059, China

${ }^{c}$ College of Architecture and Environment, Sichuan University, Chengdu 610065, China photogenerated pairs can be inhibited effectively, owing to the combination of $\mathrm{TiO}_{2}$ and $\mathrm{SnO}_{2}{ }^{25}$

The Sn dopant content plays a key role in the photocatalytic activity of $\mathrm{TiO}_{2}$ since there is an optimal concentration. The doping effect cannot be fully exhibited when the doping content is too low. However, Sn ions form recombination centers for the photogenerated pairs when the concentration surpasses the optimal content. Chua et al. ${ }^{26}$ prepared Sn-doped $\mathrm{TiO}_{2}$ films via aerosol assisted chemical vapor deposition and found that the degradation of stearic acid reached the highest value when the $\mathrm{Sn} / \mathrm{Ti}$ atom ratio was $3.8 \%$. Besides this, heat treatment affects the crystal structure of $\mathrm{TiO}_{2}$ significantly and thus annealing temperature is a decisive factor in the photocatalytic performance of $\mathrm{TiO}_{2}$. There is usually a transition from an anatase structure to a rutile structure with increasing annealing temperature. The anatase/rutile phase transition temperature is strongly affected by ion doping. The doping of several ions, such as $\mathrm{Nd}^{27}{ }^{27}{ }^{28}{ }^{28} \mathrm{Fe},{ }^{29}$ et al., raises the temperature. Meanwhile, doping with Sn reduces the temperature and promotes the transition from anatase to rutile. Alves et al. ${ }^{21}$ reported that pure $\mathrm{TiO}_{2}$, which demonstrated a single anatase structure, presented excellent photocatalytic activity after annealing at a temperature of $650{ }^{\circ} \mathrm{C}$. At the same temperature, $0.5 \mathrm{wt} \%$ Sn-doped $\mathrm{TiO}_{2}$, which consisted of $82.4 \%$ anatase and $17.6 \%$ rutile, showed the highest photocatalytic efficiency.

In view of the above, both the heat treatment temperature and doping concentration have important impacts on the crystal structure and photocatalytic activity of $\mathrm{TiO}_{2}$. Therefore, in the present work, pure and $\mathrm{Sn}$-doped $\mathrm{TiO}_{2}$ with various amounts of $\mathrm{Sn}^{4+}$ ions were synthesized via a sol-gel method and the influence of the heat treatment temperature and $\mathrm{Sn}^{4+}$ 
doping concentration on the crystal structure and the photocatalytic activity of $\mathrm{TiO}_{2}$ were studied systematically.

\section{Experimental}

\section{Preparation of pure and Sn-doped $\mathrm{TiO}_{2}$ nanomaterials}

All the $\mathrm{TiO}_{2}$ nanomaterials were prepared via a sol-gel method. In a typical preparation of pure $\mathrm{TiO}_{2}, 30 \mathrm{~mL}$ tetrabutyl titanate and $60 \mathrm{~mL}$ absolute ethanol were added into a beaker. $6 \mathrm{~mL}$ deionized water, $15 \mathrm{~mL}$ acetic acid, and $45 \mathrm{~mL}$ absolute ethanol were added into a pear-shaped funnel. The solution in the pearshaped funnel was added to the beaker dropwise with continuous stirring. After several hours of aging, the resulting sol formed a gel. The gel was dried at $80^{\circ} \mathrm{C}$ for 12 hours and was then annealed for 2 hours at $350{ }^{\circ} \mathrm{C}, 500{ }^{\circ} \mathrm{C}$, and $650{ }^{\circ} \mathrm{C}$, respectively. Sn-doped $\mathrm{TiO}_{2}$ with atom ratios $(\mathrm{Sn} / \mathrm{Ti})$ of $1 \%$, $2.5 \%, 5 \%, 10 \%$, and $15 \%$ was prepared from appropriate amounts of $\mathrm{SnCl}_{4} \cdot 5 \mathrm{H}_{2} \mathrm{O}$ being added into a pear-shaped funnel whilst the other experimental conditions were kept equal. For simplicity, $X \%$ Sn-doped $\mathrm{TiO}_{2}$ is labelled as $X \% \mathrm{Sn}-\mathrm{TiO}_{2}(X=1$, $2.5,5,10,15)$.

\section{Characterization}

X-ray diffraction (XRD) spectra were recorded with a diffractometer (DX-2700, China). Thermogravimetric (TG) and differential thermal analysis (DTA) were performed using a thermal analyzer (STA409PC, Germany). X-ray photoelectron spectra (XPS) were recorded using a spectrometer (XSAM800, Britain) to examine the chemical states. The UV-vis diffused reflectance spectra (DRS) were collected using a spectrophotometer (UV3600 , Japan). The surface morphologies (SEM) and element compositions (EDS) were determined using a field-emission scanning electron microscope (FEI-Inspect F50, USA) equipped with an energy dispersive X-ray spectrometer. Specific surface areas were measured using BET theory on the nitrogen adsorption-desorption data. Photoluminescence (PL) spectra were obtained using a luminescence spectrometer (F-4600, Japan) with a $150 \mathrm{~W}$ Xenon lamp as an excitation source.

\section{Photocatalytic activity experiments}

The photocatalytic activity of the prepared $\mathrm{TiO}_{2}$ nanomaterials was evaluated from the degradation of rhodamine $\mathrm{B}(\mathrm{RhB})$. $300 \mathrm{~mL} \mathrm{RhB}$ solution $\left(10 \mathrm{mg} \mathrm{L}^{-1}\right)$ and $0.3 \mathrm{~g} \mathrm{\textrm {TiO } _ { 2 }}$ sample were added into a beaker and the suspension was stirred for $30 \mathrm{~min}$ in darkness to establish an adsorption-desorption equilibrium between the photocatalysts and RhB molecules. A $250 \mathrm{~W}$ highpressure mercury lamp was employed as a UV light source. The degradation of $\mathrm{RhB}$ was monitored by measuring the absorbance of the $\mathrm{RhB}$ solution at $553 \mathrm{~nm}$. The degradation rate $(D)$ was calculated by the following equation:

$$
D=\left(A_{0}-A_{t}\right) / A_{0}
$$

where $A_{0}$ and $A_{t}$ are the initial absorbance and absorbance at time " $t$ ", respectively.

\section{Results and discussion}

\section{XRD analysis}

The XRD patterns of pure $\mathrm{TiO}_{2}$ and $\mathrm{Sn}-\mathrm{TiO}_{2}$ with different concentrations of Sn, annealed at $350{ }^{\circ} \mathrm{C}, 500{ }^{\circ} \mathrm{C}$, and $650{ }^{\circ} \mathrm{C}$, are shown in Fig. 1. In Fig. 1a, the patterns of all the samples are similar and the peaks can be assigned to the anatase structure. The width of the peaks is relatively wide and the intensity of the peaks is weak, which indicates that both pure $\mathrm{TiO}_{2}$ and $\mathrm{Sn}-\mathrm{TiO}_{2}$ show poor crystallinity at a temperature of $350{ }^{\circ} \mathrm{C}$.

The peak intensity of pure $\mathrm{TiO}_{2}$ increases and the peak width narrows as annealing temperature is increased to $500^{\circ} \mathrm{C}$, which suggests that the crystallinity of $\mathrm{TiO}_{2}$ increases with increasing temperature. The crystallinity of pure $\mathrm{TiO}_{2}$ annealed at $350{ }^{\circ} \mathrm{C}$ is determined to be $23.7 \%$, while it is $74.5 \%$ for pure $\mathrm{TiO}_{2}$ annealed at $500{ }^{\circ} \mathrm{C}$. There is no peak for the rutile structure, which suggests that $500{ }^{\circ} \mathrm{C}$ is insufficient for starting the phase transformation from anatase to rutile. $1 \% \mathrm{Sn}-\mathrm{TiO}_{2}$ shows a similar pattern to pure $\mathrm{TiO}_{2}$. The rutile peaks appear when the Sn doping concentration reaches $2.5 \%$. The $\mathrm{SnO}_{2}$ peaks can be detected in the patterns of $10 \% \mathrm{Sn}-\mathrm{TiO}_{2}$ and $15 \% \mathrm{Sn}-\mathrm{TiO}_{2}$, indicating that $\mathrm{SnO}_{2}$ forms in $\mathrm{Sn}-\mathrm{TiO}_{2}$ when the Sn content is at a sufficiently high level.

It is observed that both anatase and rutile peaks appear in the pattern of pure $\mathrm{TiO}_{2}$ at $650{ }^{\circ} \mathrm{C}$, which means that phase transition from anatase to rutile occurs with increasing temperature. The anatase structure peaks become weaker in the $\mathrm{Sn}-\mathrm{TiO}_{2}$ patterns, and even disappear when the Sn content is $10 \%$ and $15 \%$. There is little $\mathrm{SnO}_{2}$ forming in the $15 \% \mathrm{Sn}-\mathrm{TiO}_{2}$ sample.

The average crystallite size $(D)$ was calculated by the formula $D=0.89 \lambda / \beta \cos \theta$ (ref. 30) (where $\lambda$ is the wavelength of $\mathrm{Cu} \mathrm{K} \alpha$, $\beta$ is the full width at half maximum of the XRD peak, and $\theta$ is the Bragg diffraction angle) and the mass fraction of anatase $\left(X_{\mathrm{A}}\right)$ was calculated by the formula $X_{\mathrm{A}}=\left(1+1.26\left(I_{\mathrm{R}} / I_{\mathrm{A}}\right)\right)^{-1}$ (ref. 31) (where $I_{\mathrm{A}}$ and $I_{\mathrm{R}}$ are the intensities of the anatase (101) plane and rutile (110) plane) and all the results are shown in Table 1. The crystallite size of pure $\mathrm{TiO}_{2}$ increases with increasing temperature. $\mathrm{Sn}-\mathrm{TiO}_{2}$ shows a smaller crystallite size compared to pure $\mathrm{TiO}_{2}$ at the same temperature and the decreasing trend increases with increasing Sn content.

As shown by the results in Table 1, it is clear that the mass percentage of rutile increases with increasing Sn content, suggesting that the transition from anatase to rutile is promoted and the phase transformation temperature is reduced by $\mathrm{Sn}$ doping. There are several explanations for this phenomenon. Tripathi $e t ~ a l .{ }^{23}$ believe that higher surface energy is beneficial for the phase transformation. Anatase of smaller size has a higher surface energy and higher surface area and, therefore, it is easier to start the transformation. This viewpoint is still somewhat disputed. The doping of elements such as $\mathrm{La}^{28}$ and $\mathrm{Ce}^{32}$ in $\mathrm{TiO}_{2}$ always leads to a reduction in crystallite size. However, the phase transformation is inhibited and the transition temperature is evidently enhanced. Ding et $a l^{33}$ are convinced that the melting point of $\mathrm{M}_{X} \mathrm{O}_{Y}$ ( $\mathrm{M}$ is the doping element) is a key factor in the anatase-rutile phase 

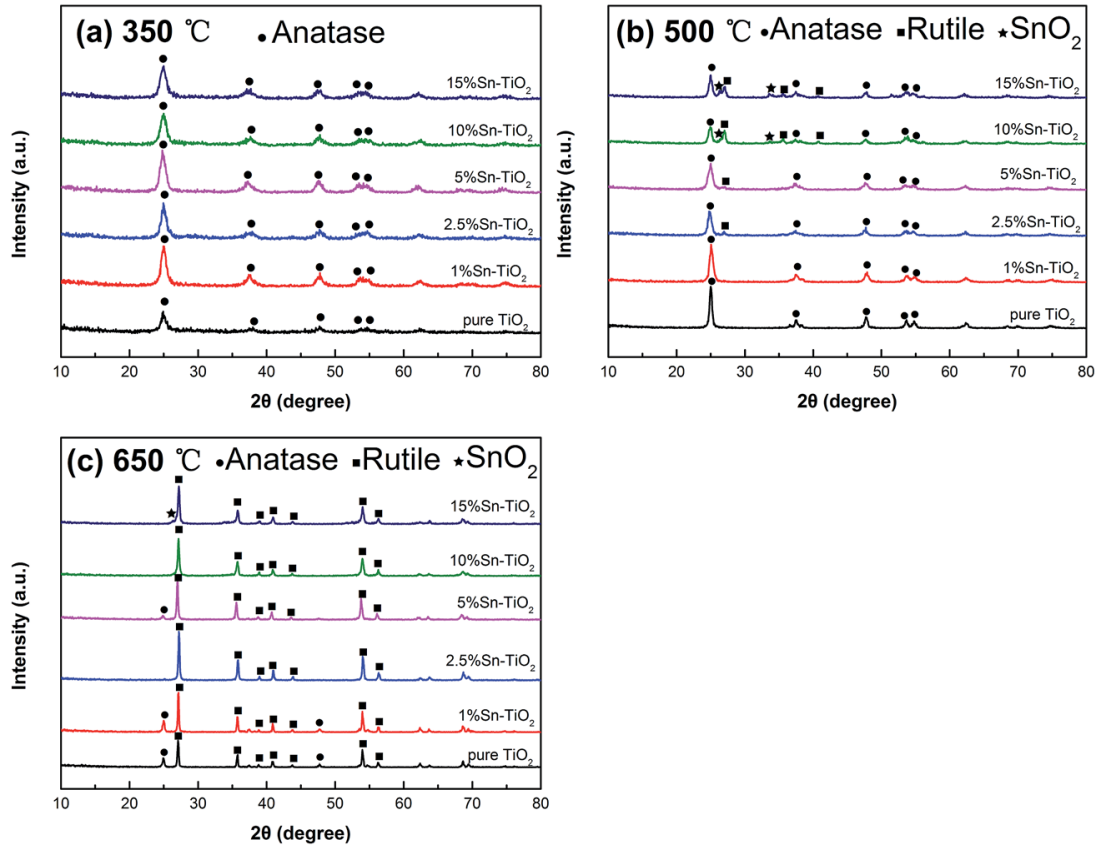

Fig. 1 XRD patterns of pure $\mathrm{TiO}_{2}$ and $\mathrm{Sn}-\mathrm{TiO}_{2}$ annealed at $350{ }^{\circ} \mathrm{C}(\mathrm{a}), 500{ }^{\circ} \mathrm{C}$ (b), and $650{ }^{\circ} \mathrm{C}$ (c).

transformation. The phase transformation will be promoted if the melting point of $\mathrm{M}_{X} \mathrm{O}_{Y}$ is lower than that of $\mathrm{TiO}_{2}\left(1640{ }^{\circ} \mathrm{C}\right)$ and it will be restrained when the melting point of $\mathrm{M}_{X} \mathrm{O}_{Y}$ is higher than that of $\mathrm{TiO}_{2}$. The melting point of $\mathrm{SnO}_{2}$ is $1127^{\circ} \mathrm{C}$, which is much lower than $\mathrm{TiO}_{2}$, and thus the addition of $\mathrm{Sn}$ promotes the phase transformation. Besides this, Kumar et al. ${ }^{34}$ and Merhraz et al. ${ }^{35}$ hold that the phase structure of $\mathrm{SnO}_{2}$ is similar to the rutile structure, which is in favor of the formation of the rutile phase during the phase transition. Consequently, the phase transformation temperature is reduced. In the present study, we believe the relatively low melting point of
$\mathrm{SnO}_{2}$ and the structural similarity between $\mathrm{SnO}_{2}$ and $\mathrm{TiO}_{2}$ are propitious to the transition from anatase to rutile. There has been considerable research to demonstrate that $\mathrm{TiO}_{2}$ with an anatase structure or anatase/rutile mix structure exhibits excellent photocatalytic activity. From the discussion above, both the heat treatment temperature and Sn doping content affect the phase structure and further affect the photocatalytic activity of $\mathrm{TiO}_{2}$. This provides a feasible method to regulate the phase structure and obtain better photocatalytic activity for $\mathrm{TiO}_{2}$ via combining a proper heat treatment temperature and doping amount.

Table 1 Crystal structure and crystallite size of all the $\mathrm{TiO}_{2}$ nanomaterials

\begin{tabular}{lll}
\hline & & \\
Temperature & Cample & Crystal structure \\
size/nm
\end{tabular}




\section{TG and DTA analyses}

The thermal behavior and weight loss curves of pure $\mathrm{TiO}_{2}$ and $10 \% \mathrm{Sn}-\mathrm{TiO}_{2}$ are shown in Fig. 2. The TG curves of both samples are divided into three steps that are attributed to the evaporation of physically adsorbed water, the combustion of organic compounds, and dehydroxylation, respectively. ${ }^{20}$ However, the total weight loss of $38.91 \%$ of $10 \% \mathrm{Sn}-\mathrm{TiO}_{2}$, especially in the second stage with a weight loss of $14.32 \%$, is more than that of the pure $\mathrm{TiO}_{2}$ sample, which indicates higher residual organic species losses in $10 \%$ $\mathrm{Sn}-\mathrm{TiO}_{2} \cdot{ }^{23}$

As shown by the DTA curves, the exothermic and endothermic peaks of both samples are caused by the decomposition of physically adsorbed water and organic compounds at a temperature below $450{ }^{\circ} \mathrm{C}$. Beyond $581{ }^{\circ} \mathrm{C}$, the exothermic peak in the DTA curve reflects the phase transformation from anatase to rutile $\mathrm{TiO}_{2}$. The exothermic peak of pure $\mathrm{TiO}_{2}$ at approximately $581{ }^{\circ} \mathrm{C}$ can be attributed to both the combustion of organic compounds and the phase transition from anatase to rutile. ${ }^{7}$ Meanwhile, it is noticeable that the exothermic peak of $10 \% \mathrm{Sn}-\mathrm{TiO}_{2}$ is around $481{ }^{\circ} \mathrm{C}$, which is lower than $581{ }^{\circ} \mathrm{C}$, suggesting that the phase transformation temperature of anatase to rutile decreases with Sn doping. It is obvious that the phase transformation from anatase to rutile is promoted by $\mathrm{Sn}$ addition, which is in agreement with the XRD analysis in Fig. 1.

\section{EDS and XPS analyses}

Fig. 3 shows the EDS spectrum of $5 \% \mathrm{Sn}-\mathrm{TiO}_{2}$ annealed at $500{ }^{\circ} \mathrm{C}$. The signals of the elements $\mathrm{Ti}, \mathrm{O}$, and $\mathrm{Sn}$ appear in the pattern, which confirms that Sn exists in the $\mathrm{TiO}_{2}$ sample.

To identify the chemical valence states of the existing elements in $\mathrm{TiO}_{2}$, XPS measurement was carried out and the results for pure $\mathrm{TiO}_{2}$ and $5 \% \mathrm{Sn}-\mathrm{TiO}_{2}$ annealed at $500{ }^{\circ} \mathrm{C}$ are shown in Fig. 4. The total spectra of pure $\mathrm{TiO}_{2}$ and $5 \% \mathrm{Sn}-\mathrm{TiO}_{2}$ are depicted in Fig. 4a, in which the signals of $\mathrm{C}, \mathrm{Ti}$, and $\mathrm{O}$ can be detected in pure $\mathrm{TiO}_{2}$. Meanwhile, a peak of $\mathrm{Sn} 3 \mathrm{~d}$ appears in $5 \% \mathrm{Sn}-\mathrm{TiO}_{2}$, which confirms that $\mathrm{Sn}$ exists in $\mathrm{TiO}_{2}$ via doping. The peaks of $\mathrm{C} 1 \mathrm{~s}$ can be attributed to oil pollution from the equipment.

The high-resolution spectra of $\mathrm{Ti} 2 \mathrm{p}$ are shown in Fig. $4 \mathrm{~b}$. There are two peaks of pure $\mathrm{TiO}_{2}$ at $458.33 \mathrm{eV}$ and $463.99 \mathrm{eV}$, which are assigned to Ti $2 \mathrm{p}_{3 / 2}$ and Ti $2 \mathrm{p}_{1 / 2}$, respectively. The peak position of $\mathrm{Ti} 2 \mathrm{p}_{3 / 2}$ and $\mathrm{Ti} 2 \mathrm{p}_{1 / 2}$ suggests that $\mathrm{Ti}$ exists as $\mathrm{Ti}^{4+} \cdot{ }^{20,36}$ Compared to pure $\mathrm{TiO}_{2}$, the Ti $2 \mathrm{p}$ of $5 \% \mathrm{Sn}-\mathrm{TiO}_{2}$ exhibits a slight positive shift, probably derived from the band bending, which is the consequence of the interaction between $\mathrm{Sn}, \mathrm{Ti}$, and $\mathrm{O}^{37,38}$

Fig. 4c shows the high-resolution spectra of the $\mathrm{O} 1 \mathrm{~s}$ of pure $\mathrm{TiO}_{2}$ and $5 \% \mathrm{Sn}-\mathrm{TiO}_{2}$. The $\mathrm{O}$ 1s of pure $\mathrm{TiO}_{2}$ consists of two peaks, located at $529.94 \mathrm{eV}$ and $532.13 \mathrm{eV}$, corresponding to lattice oxygen and surface hydroxyl groups, respectively. ${ }^{25,37,39}$ Similarly, the O 1 s of $5 \% \mathrm{Sn}-\mathrm{TiO}_{2}$ can also be divided into two peaks at $529.76 \mathrm{eV}$ and $532.39 \mathrm{eV}$ ascribed to lattice oxygen and
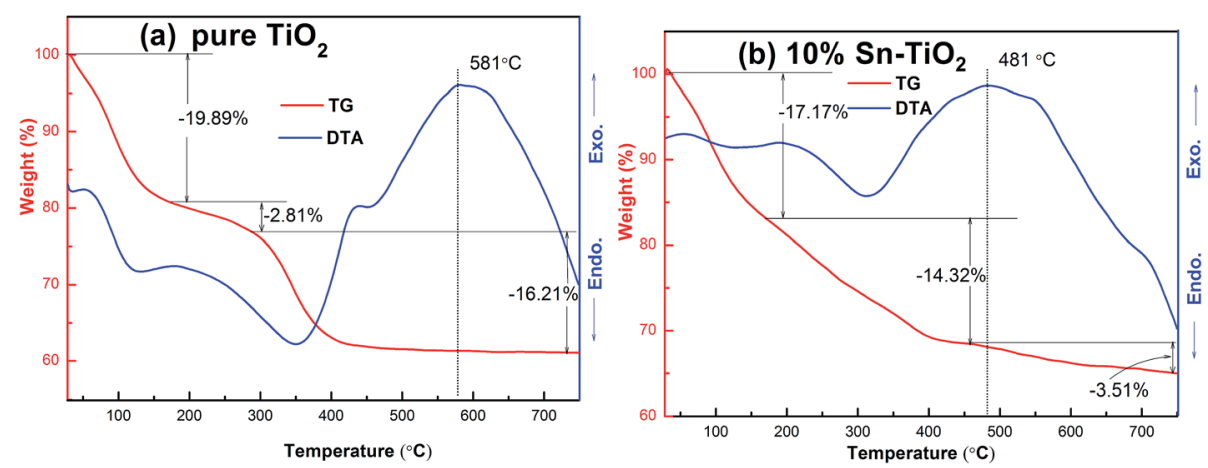

Fig. 2 TG and DTA curves for pure $\mathrm{TiO}_{2}$ and $10 \% \mathrm{Sn}-\mathrm{TiO}_{2}$.

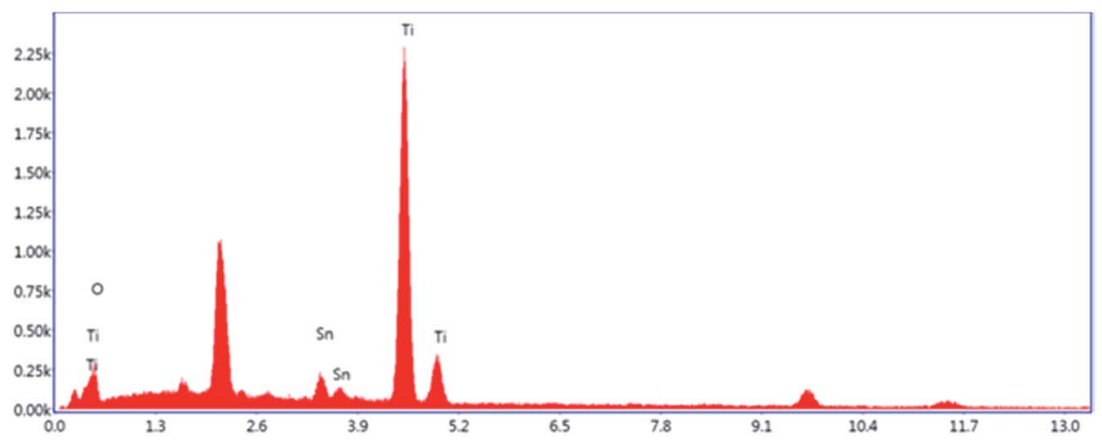

Fig. 3 EDS spectrum of $5 \% \mathrm{Sn}-\mathrm{TiO}_{2}$ annealed at $500{ }^{\circ} \mathrm{C}$. 

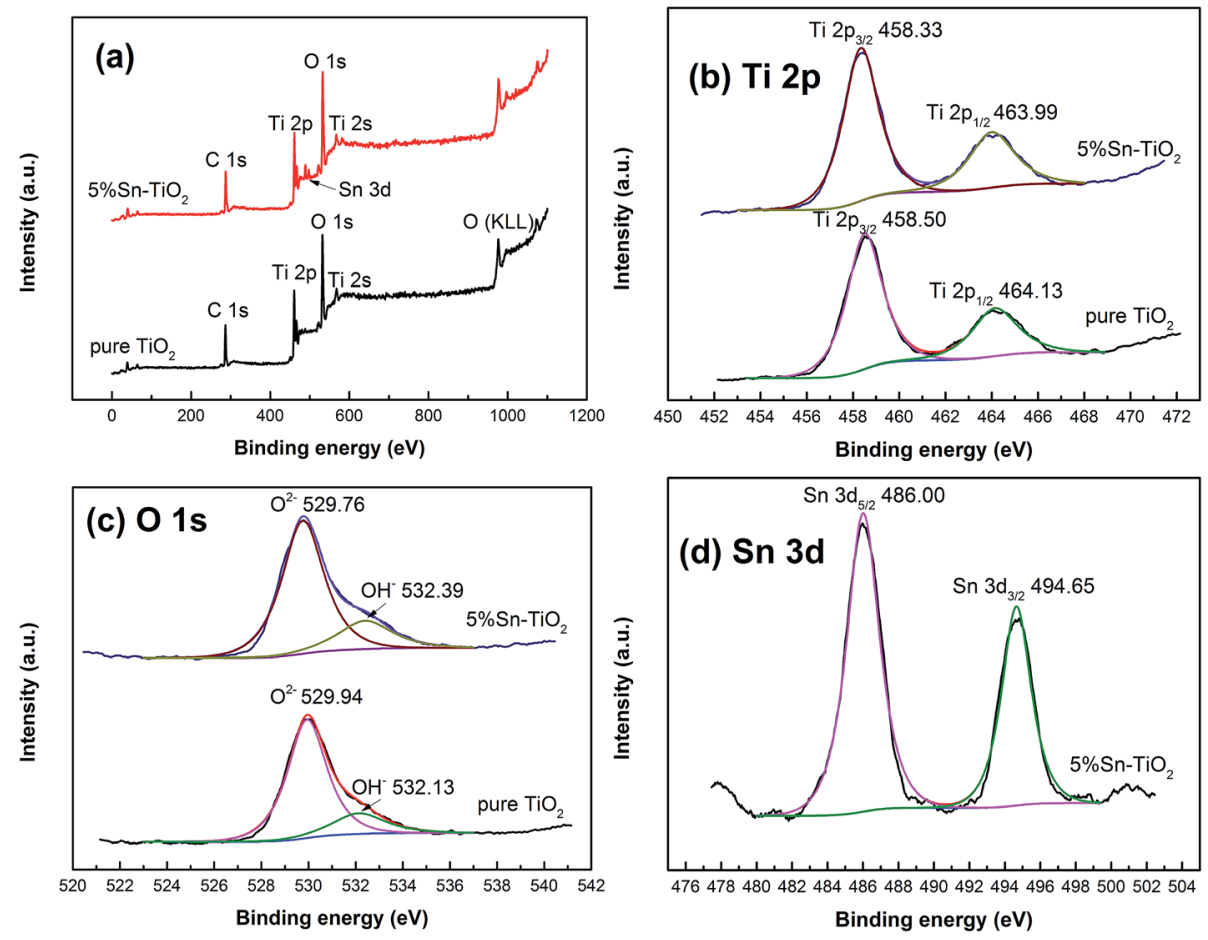

Fig. 4 The total spectra of pure $\mathrm{TiO}_{2}$ and $5 \% \mathrm{Sn}-\mathrm{TiO}_{2}$ annealed at $500{ }^{\circ} \mathrm{C}$.

surface hydroxyl groups. The ratio of surface hydroxyl groups in pure $\mathrm{TiO}_{2}$ is calculated to be $18.9 \%$ and it is $21.3 \%$ in $5 \% \mathrm{Sn}-$ $\mathrm{TiO}_{2}$. It is obvious that the number of surface hydroxyl groups increases after Sn doping, which is conducive to the photocatalytic process. ${ }^{25,39}$

Fig. $4 \mathrm{~d}$ depicts the high-resolution spectrum of Sn $3 \mathrm{~d}$ with two peaks at $486.00 \mathrm{eV}$ and $494.65 \mathrm{eV}$. These two peaks correspond to $S n 3 d_{5 / 2}$ and Sn $3 d_{3 / 2}$, respectively, indicating that the Sn is in the +4 state. $^{20,25}$

\section{DRS analysis}

The influence of the addition of Sn on the optical properties of $\mathrm{TiO}_{2}$ is controversial. Several studies report that a red shift occurs upon Sn doping. ${ }^{16,17,23,40}$ On the contrary, others have concluded that the band gap energy of $\mathrm{TiO}_{2}$ increases, thus presenting a blue shift after the addition of Sn. ${ }^{19,25}$ Fig. 5 depicts the DRS spectra of pure $\mathrm{TiO}_{2}$ and $\mathrm{Sn}-\mathrm{TiO}_{2}$ annealed at $500{ }^{\circ} \mathrm{C}$. The band gap of $\mathrm{TiO}_{2}$ is calculated following the Kubelka-Monk function: ${ }^{23}$

$$
(\alpha h \nu)^{1 / 2}=A\left(h \nu-E_{\mathrm{g}}\right)
$$

where $\alpha$ is the absorption coefficient, $h \nu$ is the photon energy, $A$ is the proportionality constant, and $E_{\mathrm{g}}$ is the band gap energy.

The band gap energy of pure $\mathrm{TiO}_{2}$ is $3.20 \mathrm{eV}$, which is in accordance with the theoretical value. The $\mathrm{Sn}-\mathrm{TiO}_{2}$ samples show a slight blue shift compared to pure $\mathrm{TiO}_{2}$. The band gap energy of $1 \% \mathrm{Sn}-\mathrm{TiO}_{2}, 2.5 \% \mathrm{Sn}-\mathrm{TiO}_{2}, 5 \% \mathrm{Sn}-\mathrm{TiO}_{2}, 10 \% \mathrm{Sn}-$ $\mathrm{TiO}_{2}$, and $15 \% \mathrm{Sn}-\mathrm{TiO}_{2}$ are determined to be $3.32 \mathrm{eV}, 3.27 \mathrm{eV}$,
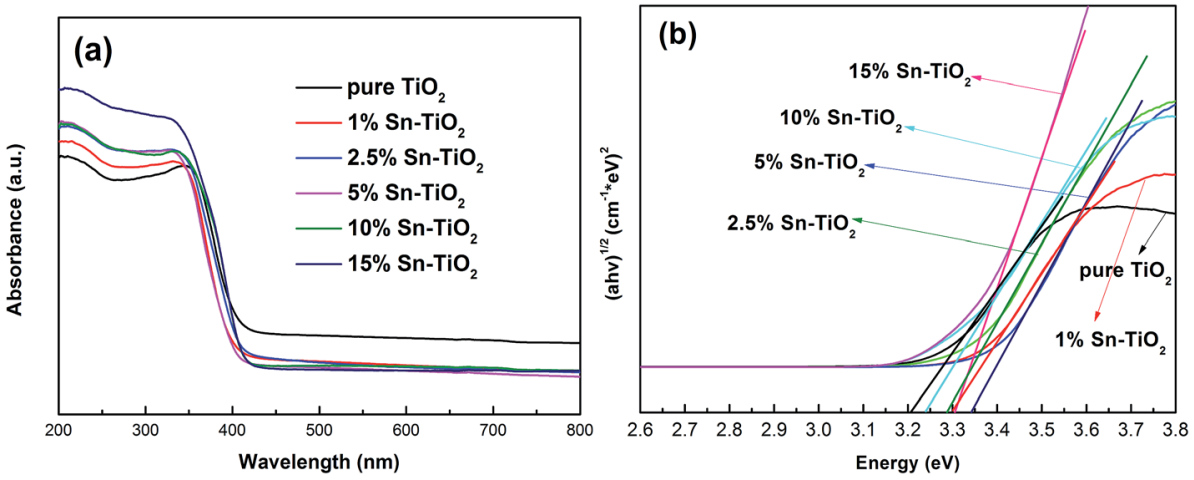

Fig. 5 (a) UV-vis diffuse reflectance absorption spectra of pure $\mathrm{TiO}_{2}$ and $\mathrm{Sn}-\mathrm{TiO}_{2}$ annealed at $500{ }^{\circ} \mathrm{C}$. (b) Optical band gap of pure $\mathrm{TiO}$ and $\mathrm{Sn}-$ $\mathrm{TiO}_{2}$. 
$3.31 \mathrm{eV}, 3.28 \mathrm{eV}$, and $3.27 \mathrm{eV}$, respectively. Obviously, the blue shift in the present work is in accordance with Bhange's and Zhao' work. ${ }^{19,25}$ Since size quantization effects come into play when the crystallite size is below $10 \mathrm{~nm},{ }^{19}$ the reason for the blue shift effect on account of Sn doping should not be ascribed to size quantization effects because the crystallite size of Sn$\mathrm{TiO}_{2}$ is from 13.5 to $17.6 \mathrm{~nm}$. The explanation for the blue shift is that the ionic radius of $\mathrm{Sn}^{4+}$ is close to that of $\mathrm{Ti}^{4+}$, and it is possible for $\mathrm{Sn}^{4+}$ ions to substitute $\mathrm{Ti}^{4+}$ ions in $\mathrm{TiO}_{2}$ lattices, changing the electronic structure of $\mathrm{TiO}_{2}$ and forming new energy levels. ${ }^{19}$

\section{SEM analysis}

Fig. 6 depicts the SEM images of pure $\mathrm{TiO}_{2}$ (a) and $5 \% \mathrm{Sn}-\mathrm{TiO}_{2}$ (b) annealed at $500{ }^{\circ} \mathrm{C}$. The particles in the pure $\mathrm{TiO}_{2}$ sample show an irregular shape and large size distribution. The agglomerated bulks have a diameter in the range of $0.1-3 \mu \mathrm{m}$. By comparison, $5 \% \mathrm{Sn}-\mathrm{TiO}_{2}$ consists of smaller particles and exhibits relatively better distribution. The smaller particle size creates more reaction points, which is beneficial for photocatalytic degradation.

\section{BET analysis}

The surface area of the samples was measured using BET theory on the nitrogen adsorption-desorption data and the results are shown in Table 2. The BET surface areas of pure $\mathrm{TiO}_{2}, 1 \% \mathrm{Sn}-$ $\mathrm{TiO}_{2}, 5 \% \mathrm{Sn}-\mathrm{TiO}_{2}$, and $15 \% \mathrm{Sn}-\mathrm{TiO}_{2}$ annealed at $500{ }^{\circ} \mathrm{C}$ are 2.9 , $13.8,54.4$, and $61.2 \mathrm{~m}^{2} \mathrm{~g}^{-1}$, respectively. It is obvious that the surface area increases tremendously after adding Sn. A higher Sn dopant level facilitates the enhancement of the surface area. The increased surface area can enhance the absorption of the light source, which contributes to the photocatalytic activity of $\mathrm{TiO}_{2}{ }^{16}$

\section{PL analysis}

Since photoluminescence (PL) emission is derived from the recombination of photogenerated electrons and holes, it can therefore provide accurate data of the recombination and separation of photogenerated pairs..$^{\mathbf{2 9 , 4 1}}$ The photoluminescence spectra of pure $\mathrm{TiO}_{2}$ and $\mathrm{Sn}-\mathrm{TiO}_{2}$ annealed at $500{ }^{\circ} \mathrm{C}$ are shown
Table 2 The BET surface area of the pure $\mathrm{TiO}_{2}$ and $\mathrm{Sn}-\mathrm{TiO}_{2}$ samples annealed at $500^{\circ} \mathrm{C}$

\begin{tabular}{lc}
\hline Sample & $\begin{array}{c}\text { BET surface } \\
\text { area }\left(\mathrm{m}^{2} \mathrm{~g}^{-1}\right)\end{array}$ \\
\hline Pure $\mathrm{TiO}_{2}$ & 2.9 \\
$1 \% \mathrm{Sn}-\mathrm{TiO}_{2}$ & 13.8 \\
$5 \% \mathrm{Sn}-\mathrm{TiO}_{2}$ & 54.4 \\
$15 \% \mathrm{Sn}-\mathrm{TiO}_{2}$ & 61.2 \\
\hline
\end{tabular}

in Fig. 7. The intensity of the emission spectra is observed to decrease with Sn concentration up to $5 \% . \mathrm{Sn}^{4+}$ ions act as a trap for photogenerated electrons, thus increasing the separation rate of the photogenerated pairs. ${ }^{17}$ However, the intensity of the PL spectrum increases in the $10 \% \mathrm{Sn}-\mathrm{TiO}_{2}$, which indicates that further Sn doping content is harmful and increases the recombination of the photogenerated pairs. Unexpectedly, the PL spectrum intensity of $15 \% \mathrm{Sn}-\mathrm{TiO}_{2}$ is lower than that of $10 \%$ $\mathrm{Sn}-\mathrm{TiO}_{2}$. Bhange et al. ${ }^{19}$ hold that the decrease in PL intensity at high $\mathrm{Sn}$ doping levels is derived from the formation of $\mathrm{SnO}_{2}$. The photogenerated electrons are able to move to the conduction band of $\mathrm{SnO}_{2}$ from the $\mathrm{TiO}_{2}$ surface, which improves the separation of the photogenerated pairs.

\section{Photocatalytic activity}

The photocatalytic activity of all the prepared samples was investigated via the decomposition of RhB solution. The degradation rates of $\mathrm{RhB}$ under UV light over pure $\mathrm{TiO}_{2}$ and $\mathrm{Sn}-$ $\mathrm{TiO}_{2}$ heat treated at $350{ }^{\circ} \mathrm{C}, 500{ }^{\circ} \mathrm{C}$, and $650{ }^{\circ} \mathrm{C}$ are shown in Fig. 8. The prepared $\mathrm{TiO}_{2}$ nanomaterials that were heat treated at $350{ }^{\circ} \mathrm{C}$ show degradation rates of $46.2 \%, 99.5 \%, 99.2 \%$, $96.7 \%, 92.2 \%$, and $85.1 \%$ with an Sn dopant concentration of $0 \%, 1 \%, 2.5 \%, 5 \%, 10 \%$, and $15 \%$ after $180 \mathrm{~min}$. The results reveal that pure $\mathrm{TiO}_{2}$ shows relatively low photocatalytic activity at $350{ }^{\circ} \mathrm{C}$. The degradation rate of pure $\mathrm{TiO}_{2}$ annealed at $500{ }^{\circ} \mathrm{C}$ is $62.5 \%$, which is 1.35 times higher than that of pure $\mathrm{TiO}_{2}$ annealed at $350{ }^{\circ} \mathrm{C}$. This enhancement is ascribed to the increase in the degree of crystallinity with rising temperature. ${ }^{42}$

The degradation rates of $1 \% \mathrm{Sn}-\mathrm{TiO}_{2}, 2.5 \% \mathrm{Sn}-\mathrm{TiO}_{2}, 5 \% \mathrm{Sn}-$ $\mathrm{TiO}_{2}, 10 \% \mathrm{Sn}-\mathrm{TiO}_{2}$, and $15 \% \mathrm{Sn}-\mathrm{TiO}_{2}$ annealed at $500{ }^{\circ} \mathrm{C}$ are

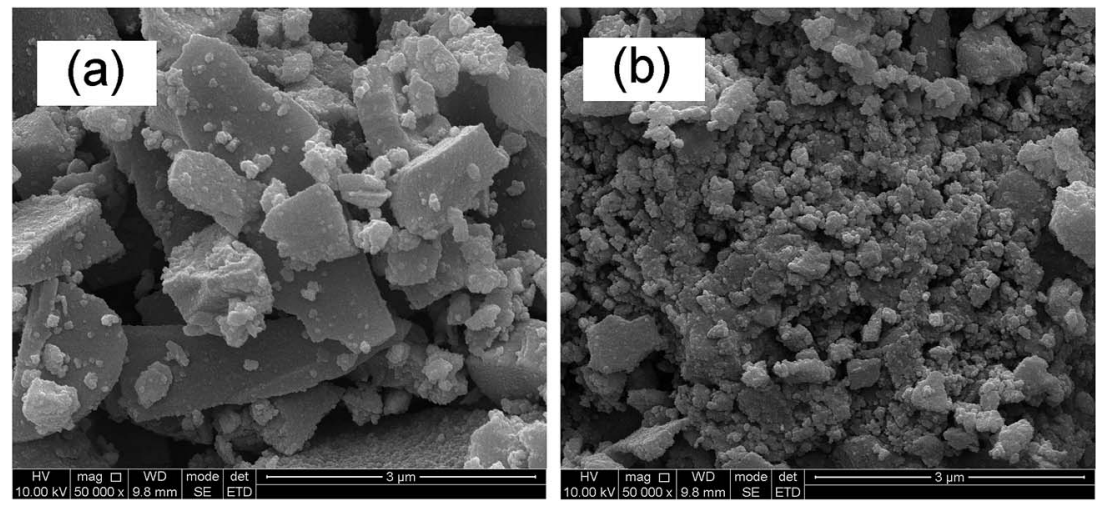

Fig. $6 \mathrm{SEM}$ images of pure $\mathrm{TiO}_{2}$ (a) and $5 \% \mathrm{Sn}-\mathrm{TiO}_{2}$ (b) annealed at $500{ }^{\circ} \mathrm{C}$. 


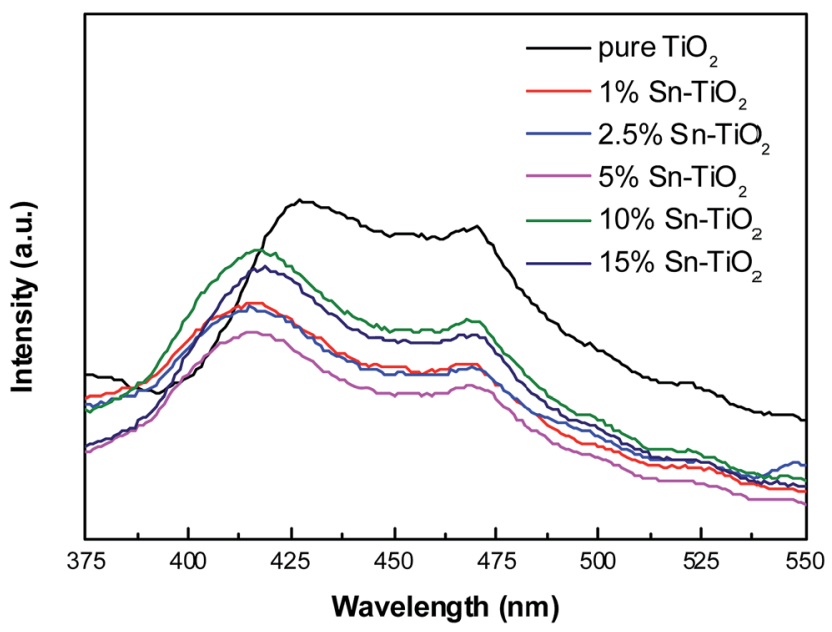

Fig. 7 Photoluminescence spectra of pure $\mathrm{TiO}_{2}$ and $\mathrm{Sn}-\mathrm{TiO}_{2}$ annealed at $500^{\circ} \mathrm{C}$.

92.8\%, 95.0\%, 96.7\%, 95.8\%, and 94.7\%, respectively. All the $\mathrm{Sn}-\mathrm{TiO}_{2}$ samples show higher degradation rates compared to that of pure $\mathrm{TiO}_{2}$, which clearly states that the photocatalytic activity of $\mathrm{TiO}_{2}$ improves significantly with $\mathrm{Sn}$ doping. From the results of the XRD and BET analyses, it is clear that $\mathrm{Sn}-\mathrm{TiO}_{2}$ nanomaterials have a smaller crystallite size and larger surface area compared to pure $\mathrm{TiO}_{2}$. The increased surface area is in favor of the photocatalytic reaction process, owing to the presence of more reaction spots. ${ }^{19}$ In addition, the lattice expansion caused by the substitution of $\mathrm{Ti}^{4+}$ ions with $\mathrm{Sn}^{4+}$ ions leads to the formation of more surface defects. The resulting defects capture photogenerated electrons and thus suppress the recombination of the photogenerated pairs effectively, ${ }^{\mathbf{1 7}}$ which is proven by the PL measurement. Besides this, from the XPS results, it is found that more surface hydroxyl groups form on the surface of $\mathrm{Sn}-\mathrm{TiO}_{2}$, indicating that the hydration ability and the adsorption ability of the RhB molecules are enhanced by Sn doping. Therefore, $\mathrm{Sn}-\mathrm{TiO}_{2}$ exhibits a higher photocatalytic activity than pure $\mathrm{TiO}_{2} \cdot{ }^{25}$ Among the samples heat treated at $350{ }^{\circ} \mathrm{C}, 1 \% \mathrm{Sn}-\mathrm{TiO}_{2}$ shows the best photocatalytic activity. A further increase in the addition of $\mathrm{Sn}$ results in a decline in the photocatalytic activity because the excess $\mathrm{Sn}^{4+}$ ions act as recombination centers for the photogenerated pairs. ${ }^{41}$ It is worth noting that $5 \% \mathrm{Sn}-\mathrm{TiO}_{2}$ exhibits the best photocatalytic activity, and $10 \% \mathrm{Sn}-\mathrm{TiO}_{2}$ and $15 \% \mathrm{Sn}-\mathrm{TiO}_{2}$ also present high photocatalytic activity. From the XRD results, it is observed that rutile $\mathrm{TiO}_{2}$ forms in the $2.5 \% \mathrm{Sn}-\mathrm{TiO}_{2}, 5 \% \mathrm{Sn}-\mathrm{TiO}_{2}, 10 \% \mathrm{Sn}-$ $\mathrm{TiO}_{2}$, and $15 \% \mathrm{Sn}-\mathrm{TiO}_{2}$ samples. The mixture of anatase and rutile can promote the transfer of photogenerated electrons, which prolongs the lifetime of the photogenerated pairs and thus improves the photocatalytic activity. ${ }^{21,24} \mathrm{SnO}_{2}$ forms in the $10 \% \mathrm{Sn}-\mathrm{TiO}_{2}$ and $15 \% \mathrm{Sn}-\mathrm{TiO}_{2}$ samples and the combination of $\mathrm{SnO}_{2}$ with $\mathrm{TiO}_{2}$ also has a mixture effect, which is beneficial to the photocatalytic activity. ${ }^{19,25}$

The degradation rates of pure $\mathrm{TiO}_{2}, 1 \% \mathrm{Sn}-\mathrm{TiO}_{2}, 2.5 \% \mathrm{Sn}-$ $\mathrm{TiO}_{2}, 5 \% \mathrm{Sn}-\mathrm{TiO}_{2}, 10 \% \mathrm{Sn}-\mathrm{TiO}_{2}$, and $15 \% \mathrm{Sn}-\mathrm{TiO}_{2}$ heat treated at $650{ }^{\circ} \mathrm{C}$ are $37.5 \%, 51.7 \%, 51.4 \%, 85.2 \%, 74.0 \%$, and $49.0 \%$, respectively. All the samples show lower photocatalytic activity compared to those treated at $500{ }^{\circ} \mathrm{C}$, owing to the high rutile content (Fig. 1c). It is well known that rutile $\mathrm{TiO}_{2}$ exhibits lower photocatalytic activity because of its poor hydroxylation and oxygen absorption. As a result, excess rutile leads to lower photocatalytic activity. ${ }^{24,43}$
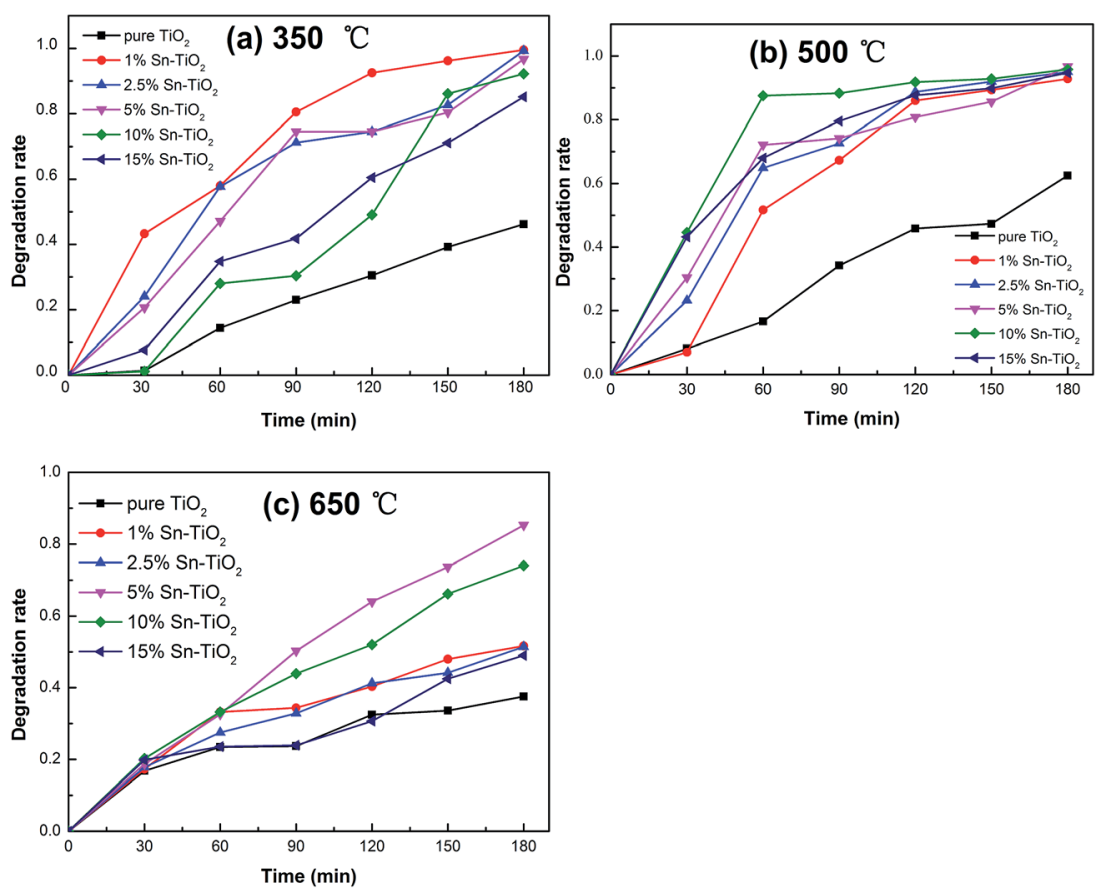

Fig. 8 Photocatalytic degradation of $\mathrm{RhB}$ for pure $\mathrm{TiO}_{2}$ and $\mathrm{Sn}-\mathrm{TiO}_{2}$ annealed at $350{ }^{\circ} \mathrm{C}$ (a), $500{ }^{\circ} \mathrm{C}$ (b), and $650{ }^{\circ} \mathrm{C}$ (c). 

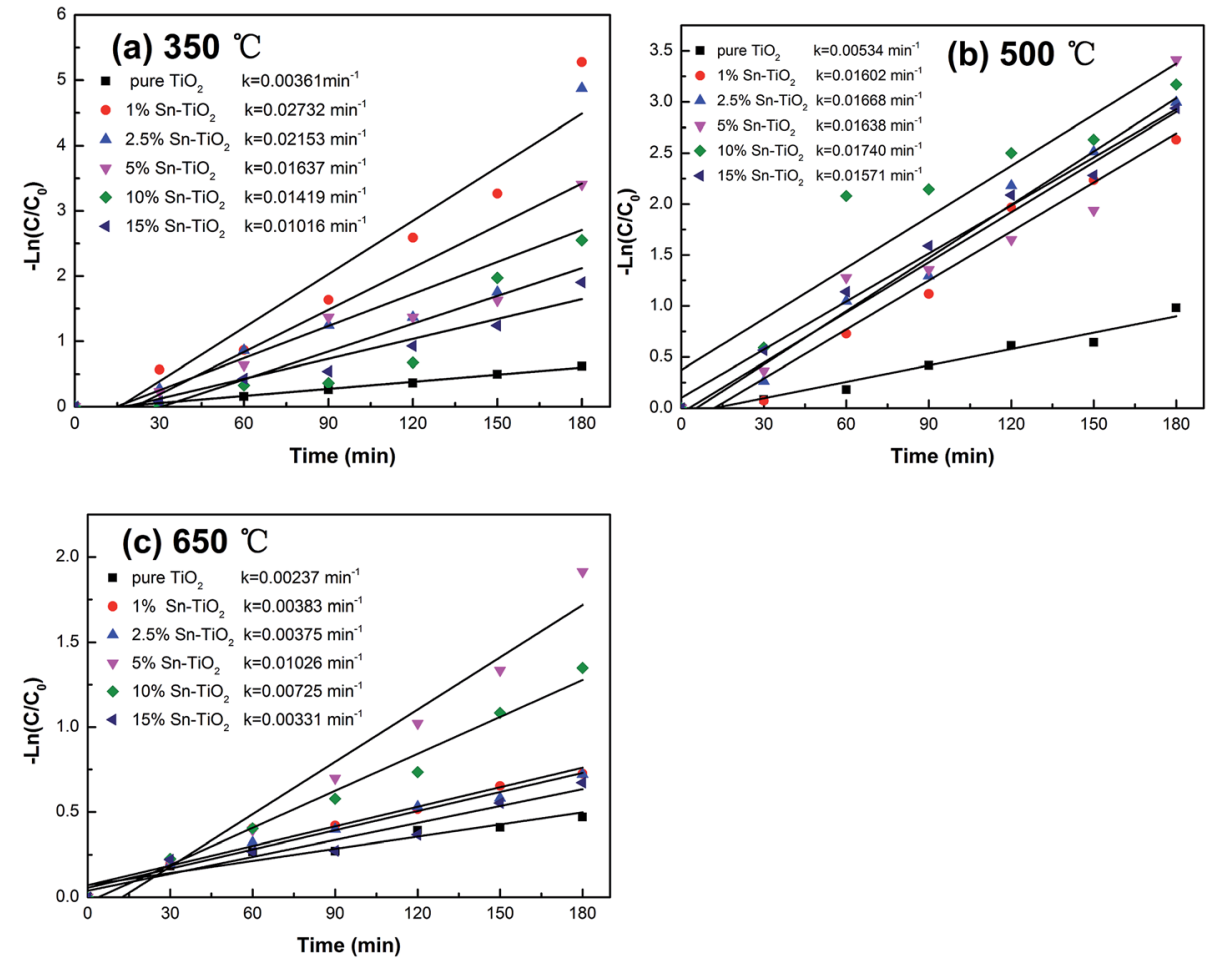

Fig. 9 First-order reaction rate constant $k$ against reaction time for different photocatalysts annealed at $350{ }^{\circ} \mathrm{C}(\mathrm{a}), 500{ }^{\circ} \mathrm{C}(\mathrm{b})$, and $650{ }^{\circ} \mathrm{C}$ (c).

The kinetics of the photocatalytic degradation of RhB can be described by a first order kinetics model and the reaction rate constant $k$ can be calculated from the following equation: ${ }^{44}$

$$
k t=-\ln \left(C_{t} / C_{0}\right)
$$

where $t$ is the reaction time, $C_{t}$ is the concentration of $\mathrm{RhB}$ at $t$ time, and $C_{0}$ is the initial concentration. The graphs of $\ln \left(C_{t} / C_{0}\right)$ versus reaction time $(t)$ for all the samples are shown in Fig. 9, which demonstrate that both the heat treat temperature and $\mathrm{Sn}$ content affect the photocatalytic activity of $\mathrm{TiO}_{2}$ significantly. The reaction constant of $1 \% \mathrm{Sn}-\mathrm{TiO}_{2}$ annealed at $350{ }^{\circ} \mathrm{C}$ is determined to be $0.027 \mathrm{~min}^{-1}$, which is 7.5 times higher than that of pure $\mathrm{TiO}_{2}$ at $350{ }^{\circ} \mathrm{C}$. The reaction constant of $10 \% \mathrm{Sn}-$ $\mathrm{TiO}_{2}$ annealed at $500{ }^{\circ} \mathrm{C}\left(0.017 \mathrm{~min}^{-1}\right)$ is 3.4 times higher than that of pure $\mathrm{TiO}_{2}\left(0.005 \mathrm{~min}^{-1}\right)$ and the reaction constant of $5 \%$ $\mathrm{Sn}-\mathrm{TiO}_{2}$ annealed at $650{ }^{\circ} \mathrm{C}\left(0.010 \mathrm{~min}^{-1}\right)$ is 5 times higher than that of pure $\mathrm{TiO}_{2}\left(0.002 \mathrm{~min}^{-1}\right)$ at the same temperature. The results indicate that the addition of Sn evidently improves the photocatalytic activity of $\mathrm{TiO}_{2}$, especially when the heat treatment temperatures are $350{ }^{\circ} \mathrm{C}$ and $650{ }^{\circ} \mathrm{C}$.

\section{Conclusion}

In summary, we reported a simple sol-gel method for the synthesis of pure $\mathrm{TiO}_{2}$ and $\mathrm{Sn}-\mathrm{TiO}_{2}$. The prepared $\mathrm{TiO}_{2}$ nanomaterials were characterized by XRD, TG, DTA, EDS, XPS, DRS, SEM, BET, and PL. The results reveal that all the samples form anatase after calcining at $350{ }^{\circ} \mathrm{C}$, while rutile appears in $\mathrm{Sn}$ $\mathrm{TiO}_{2}$ with high dopant levels at temperatures up to $500{ }^{\circ} \mathrm{C}$ and rutile is dominant at $650{ }^{\circ} \mathrm{C}$. The addition of $\mathrm{Sn}$ promotes the phase transformation from anatase to rutile. The photocatalytic test results show that both the heat treatment temperature and Sn dopant concentration affect the photocatalytic activity of $\mathrm{TiO}_{2} .1 \% \mathrm{Sn}-\mathrm{TiO}_{2}$ shows the highest degradation rate at $350{ }^{\circ} \mathrm{C}$ and $5 \% \mathrm{Sn}-\mathrm{TiO}_{2}$ exhibits the highest degradation rates at $500{ }^{\circ} \mathrm{C}$ and $650{ }^{\circ} \mathrm{C}$.

\section{Conflicts of interest}

There are no conflicts to declare.

\section{Acknowledgements}

This work was supported by the Open Research Subject of the Powder Metallurgy Engineering Technology Research Center of Sichuan Province, China (grant no. SC-FMYJ2017-03, SCFMYJ2017-05), the Key Project of the Sichuan Science and Technology Department of China (grant no. 2017GZ0402), Natural Science and Technology Research Projects of Chengdu, China (grant no. 2015-HM01-00385-SF), and the Open Research Subject of the Key Laboratory of Special Material and Preparation Technology of Sichuan Province, China (grant no. szjj2017-062).

\section{References}

1 F. Mehmood, J. Iqbal, T. Jan, A. Gul, Q. Mansoor and R. Faryal, Vib. Spectrosc., 2017, 93, 78. 
2 A. S. Pawar, S. S. Garje and N. Revaprasadu, Mater. Chem. Phys., 2016, 183, 366.

3 O. Bechambi, M. Chalbi, W. Najjar and S. Sayadi, Appl. Surf. Sci., 2015, 347, 414.

4 T. S. Jamil, H. A. Abbas, A. M. Youssief, E. S. Mansor and F. F. Hammad, Chimia Rep., 2017, 20, 97.

5 B. Choudhury, R. Verma and A. Choudhury, RSC Adv., 2014, 4, 29314.

6 M. G. Alalm, A. Tawfik and S. Ookawara, J. Environ. Chem. Eng., 2016, 4, 1929.

7 M. K. Sahnesarayi, H. Sarpoolaky and S. Rastegari, Surf. Coat. Technol., 2014, 258, 861.

8 H. J. Lin, T. S. Yang, C. S. Hsi, M. C. Wang and K. C. Lee, Ceram. Int., 2014, 40, 10633.

9 M. Iwasaki, M. Hara, H. Kawada, H. Tada and S. Ito, J. Colloid Interface Sci., 2000, 224, 202.

10 I. Horovitz, D. Avisar, M. A. Baker, R. Grilli, L. Lozzi, D. D. Camillo and H. Mamane, J. Hazard. Mater., 2016, 310, 98.

11 Y. Zhang, T. Wang, M. Zhou, Y. Wang and Z. M. Zhang, Ceram. Int., 2016, 43, 3118.

12 F. Bensouici, M. Bououdina, A. A. Dakhel, R. Tala-Ighil, M. Tounane, A. Iratni, T. Souier, S. Liu and W. Cai, Appl. Surf. Sci., 2017, 395, 110.

13 Q. Guo, Z. H. Zhang, X. P. Ma, K. Jing, M. L. Shen, N. Yu, J. H. Tang and D. D. Dionysiou, Sep. Purif. Technol., 2017, 175, 305.

14 J. Su, Z. D. Li, Y. Q. Zhang, Y. J. Wei and X. D. Wang, Catal. Today, 2017, 282, 31.

15 C. M. Malengreaux, S. L. Pirard, G. Léonard, J. G. Mahy, M. Herlitschke, B. Klobes, R. Hermann, B. Heinrichs and J. R. Bartlett, J. Alloys Compd., 2017, 691, 726.

16 J. L. Li, X. T. Xu, X. J. Liu, C. Y. Yu, D. Yan and Z. Sun, J. Alloys Compd., 2016, 679, 454.

17 R. M. Mohamed and E. S. Aazam, J. Alloys Compd., 2014, 595, 8.

18 H. B. Jiang, J. Xing, Z. P. Chen, F. Tian, Q. Cuan, X. Q. Gong and H. G. Yang, Catal. Today, 2014, 225, 18.

19 P. D. Bhange, S. V. Awate, R. S. Gholap, G. S. Gokavi and D. S. Bhange, Mater. Res. Bull., 2016, 76, 264.

20 D. A. Solís-Casados, L. Escobar-Alarcón, L. M. Gómez-Oliván, E. Haro-Poniatowski and T. Klimova, Fuel, 2017, 198, 3.

21 A. K. Alves, F. A. Berutti and C. P. Bergmann, Catal. Today, 2013, 208, 7 .
22 N. P. Tangale, P. S. Niphadkar, V. Samuel, S. S. Deshpande, P. N. Joshi and S. V. Awate, Mater. Lett., 2016, 171, 50.

23 A. K. Tripathi, M. C. Mathpal, P. Kumar, M. K. Kumar, M. A. G. Soler and A. Agarwal, J. Alloys Compd., 2015, 622, 37.

24 Q. Gao, X. M. Wu, Y. H. Ma, D. Q. Li, Y. M. Fan and C. Du, Ceram. Int., 2016, 42, 17148.

25 Y. Zhao, J. Liu, L. Y. Shi, S. Yuan, J. H. Feng, Z. Y. Wang and M. H. Zhang, Appl. Catal., B, 2011, 103, 436.

26 C. S. Chua, O. K. Tan, M. S. Tse and X. Z. Ding, Thin Solid Films, 2013, 544, 571.

27 A. Bokare, M. Pai and A. A. Athawale, Sol. Energy, 2013, 91, 111.

28 W. Zhang, X. J. Li, G. Jia, Y. F. Gao, H. Wang, Z. Z. Cao, G. H. Li and J. R. Liu, Catal. Commun., 2014, 45, 144.

29 M. Wei, J. M. Wan, Z. W. Hu, Z. Q. Peng, B. Wang and H. G. Wang, Appl. Surf. Sci., 2017, 391, 267.

30 V. Uvarov and I. Popov, Mater. Charact., 2007, 58, 883.

31 R. Spurr and H. Myers, Anal. Chem., 1957, 29, 760.

32 S. Kityakarn, Y. Pooarporn, P. Songsiriritthigul, A. Worayingyong, S. Robl, A. M. Braun and M. Wörner, Electrochim. Acta, 2012, 83, 113.

33 X. Z. Ding, L. Liu, X. M. Ma, Z. Z. Qi and Y. Z. He, Mater. Lett., 1994, 13, 462.

34 K. P. Kumar, D. J. Fray, J. Nair, F. Mizukami and T. Okubo, Scripta Mater., 2007, 57, 771.

35 S. Mehraz, P. Konsong, A. Taleb, N. Dokhane and L. Sikong, Sol. Energy Mater. Sol. Cells, 2017, DOI: 10.1016/ j.solmat.2017.06.048.

36 D. G. Huang, S. J. Liao, W. B. Zhou, S. Q. Quan, L. Liu, Z. J. He and J. B. Wan, J. Phys. Chem. Solids, 2009, 70, 853.

37 Y. D. Duan, N. Q. Fu, Q. Zhang, Y. Y. Fang, X. W. Zhou and Y. Lin, Electrochim. Acta, 2013, 107, 473.

38 Z. Zhang and J. T. Yates, Chem. Rev., 2012, 112, 5520.

39 M. V. Dozzi, L. Artiglia, G. Granozzi, B. Ohtani and E. Selli, J. Phys. Chem. C, 2014, 118, 25579.

40 F. E. Oropeza, B. Davies, R. G. Palgrave and R. G. Egdel, Phys. Chem. Chem. Phys., 2011, 13, 7882.

41 A. Kadam, R. Dhabbe, D. Shin, K. Garadkar and J. Park, Ceram. Int., 2017, 43, 5164.

42 B. Erjavec, R. Kaplan and A. Pintar, Catal. Today, 2015, 241, 15.

43 O. Carp, C. L. Huisman and A. Reller, Prog. Solid State Chem., 2004, 32, 33.

44 I. Ali, S. Kim, S. Kim and J. Kim, Catal. Today, 2016, 282, 31. 